\title{
EL MARC POLITIC DE BARCELONA '92
}

\author{
Isidre Molas
}

Resum

L'objectiu de l'article és presentar el marc politic en el qual apareixen els Jocs Olimpics de 1992. La idea neix en el context politic d'una democràcia dificilment aconseguida despres de quaranta anys de dictadura. L'alcalde socialista de Barcelona al pricipi dels anys vuitanta, Narcis Serra, proposa la nominació olimpica de Barcelona pel 1992 amb la pretensio de fer renéixer la il.lusió col-lectiva de la ciutat.

L'originalitat de la iniciativa radica, segons l'autor, en el fet que, per primera vegada en cinquanta anys, es planteja un projecte de Barcelona cap a Espanya, en el qual col. Laboren un important nombre dinstitucions - moltes d'elles en forta competència electoral, com són l'Ajuntament de Barcelona i la Generalitat de Catalunya.

Isidre Molas avalua alguns altres factors que poden tenir una incidènciat politica en els jocs: les conseqüiencies negatives del problema de coordinació entre les institucions responsables de longanització olimpica, el perill d'activitats terroristes o el risc d'esclat de minories i la incidencia de tensions per la nova confuguracio del mapa mundial, i especialment del mapa europeu.

\section{Resumen}

El abjetivo del articulo es presentar el marco politico en el que surgen los Juegos Olimpicos de 1992. La idea nace en el contexto politico de una demo. cracia dificilmente conseguida tras cuarenta años de dictadura. El alcalde socialista de Barcelona, Narcis Serra, plantea La nominación olimpica de Barcelona para 1992 con la pretensión de hacer renacer la ilusión colectiva de la ciudad.

La originalidad de la iniciativa radica, seguin el autor, en que por primera vez en cincuenta años se plantea un proyecto de Barcelona bacia España, en el que colaboran un importante número de instituciones, -algunas de ellas en fuerte competencia electoral, como son el Ayuntamiento de Barcelona y la Generalitat de Cataluña.

Isidre Molas evalua otros factores que pueden tener incidencia politica en Los Juegos: las consecuencias negativas del problema de coordinación entre las instituciones responsables de la organización olimpica, el peligro de actividades terroristas o el riesgo de explosion de minorias y la incidencia de tensiones pre- 
«Papers»: Revista de Sociologia

visibles por la nueva configuración del mapa mundial, y especialmente del mapa europeo.

Abstract

The objective of this article is to present the political context of 1992 Olympic Games. The idea of holding the Games occured in the contet of a recently established democracy following 40 years of dictatorship.

The socialist Mayor of Barcelona, Narcts Serra, proposed the olympic nomination for 1992 to the objective regaining a sense of collective bope in the city.

The originality of this approach was based, according to the author, on the fact that for the first time in fiffy years an iniciative projected Barcelona towards Spain, in which a wide range of institutions were involved -including ones which were competing electorally (municipality and the government of Catalonia).

Isidre Molas assesses other political factors: the negative consequences of the problems of coordination between different organisations, the dangers of terrorist actions and the impact of tenstons resulting from the new geo-political map of the world and especially of Europe.

Per tal de parlar sobre el marc políric dels Jocs Olímpics de Barcelona, he optat per intentar posar en relleu alguns fets que a vegades són poc subratllats en les nostres anàlisis i per recordar algunes coses que, des d'altres cultures o des d'altres enfocaments, potser hom sol oblidar de manera injusta.

Una aproximació inicial al marc en què se situen els Jocs de Barcelona de 1992 ha de partir de l'existència a Espanya d'una democràcia política, treballosament aconseguida a partir d'una voluntat generalitzada d'enterrar la nostra Guerra Civil i els seus efectes i, per tant, d'enterrar l'enfrontament i la violència en la vida política. Aquesta afirmació, que por semblar obvia, no ho és tant si recordem el plantejament del projecte de Jocs Olímpics per a la ciutat de Barcelona.

Durant els anys 1980-1981 la situació a Espanya es trobava en un camí de podriment, que podia portar al trencament de la democràcia que haviem estrenat el 1977. La dimissió del president Suárez i l'intent goyesc de cop d'Estat de Tejero del 23 de febrer de 1981 infongueren a l'ànim general - no només a l'ànim dels més informats o dels més actius - la idea que continuàvem arrossegant el liast del segle xIX, i la disminució de la confrança en les possiblitats de viure com una societat civilitzada, en què les diferents opcions que existien a Espanya treballaven conjuntament en un rumb comú, 
encara que des de punts de vista diferentes i conflictius. Els comentaris de desànim començaven a estendre's. Això coincidia amb un moment en què Barcelona vivia una situació de baixa relativa en l'esforç de direcció del procés de modernització cultural, econòmica i política, que la ciutat havia readquirit sobretot a la segona meitat de la dècada dels setanta.

En aquest context hi hagué la proposta, de l'alcalde Narcís Serra, de treballar per tal de postular i després obtenir la nominació de Barcelona com a ciutat olímpica. La idea era canviar la lògica fatalista que s'anava imposant $i$, per tant, no pensar tant allò que ens lligava a la situació que volíem abandonar, i que gairebé havíem abandonat en el període 1977-1980, sino projectar-nos en els deu o quinze anys pròxims. És a dir, situar la dècada dels noranta com l'objectiu amb què havíem de començar ja a treballar: plantejar els vuitanta com la preparació dels noranta. Hom dibuixava una il-lusió col-lectiva per a Barcelona, que no només era vàlida per a la ciutat, i un objectiu que centrés esforços a mitjà termini i que fos una iniciativa que des de Catalunya pogués obtenir l'adhesió de tot Espanya; es tractava, per tant, de plantejar un projecte de futur. El lema que en aquesta època aflorava entre els nuclis que es trobaven a prop de l'elaboració del projecte podria haver estat: "mirar endavant".

Voldria recordar aquest fet perquè l'intent de cop d'Estat de Tejeto fou el febrer de 1981, i el juny de 1981 l'Ajuntament de Barcelona decidí per unanimitat encarregar el projecte de viabilitat dels Jocs Olímpics. L'I de novembre del mateix any, a Lausana, aquest projecte fou lliurat per tres persones que després tindrien un gran pes en el seu desplegament posterior: Romà Cuyyàs, l'encarregat de la redacció del projecte, Enric Truñó, de l'Ajuntament de Barcelona, i Josep-Lluís Vilaseca, de la Generalitat de Catalunya; aquests dos darrers, membres, respectivament, dels dos partits amb més representació en l'opinió pública (el Partit dels Socialistes de Catalunya i la coalició de Convergència Democràtica i Unió Democràtica).

El projecte olímpic se situava així com un objectiu a deu anys vista, com un esperó per a capgirar una situació: es tracłava de llançar una iniciativa. d'unió i de multiplicació d'esforços i, al mateix temps, de potenciar la ciutat de Barcelona com a capital de Catalunya, com una de les dues ciutats importants d'Espanya $\dot{i}$, també, com una ciutat amb vocació europea $i$ internacional, no tancada en ella mateixa. Era el primer projecte formulat des de Barcelona, i obert a Espanya, sorgit en la nova democràcia $i$, potser en els darrers cirquanta anys, un projecte que seria potenciat i ajudat pel Govern espanyol.

Crec que aquest plantejament pot tenir interès per a entendre fets posteriors. Així, amb ef concurs dels dos partits principals de Barcelona (i l'acord dels altres), amb el suport dels governs espanyol i català, quan l'Ajuntament 
de Barcelona prengué la iniciativa, posà de manifest una de les forces de la candidatura barcelonina i indicà també una de les condicions polítiques a respectar durant deu anys: la coincidència en un esforç comú.

Però el sistema democràtic espanyol genera una competència electoral cada any entre els partits que necessiten col-laborar per tal de poder realitzar el projecte - no solament per a aconseguir la nominació. I, al mateix temps, també hi participen totes les altres forces democràtiques, que mostren el seu acord amb els Jocs i que concorren igualment en l'esforç comú de l'organització. El trencament per part de qualsevol d'aquests sectors podria significar un perill per a la nominació $i$, més tard, per a la mateixa realització amb èxit dels Jocs.

Ara falta un any per a celebrar-los. Fins avui tot el procés, dirigit per l'alcalde Pasqual Maragall, s'ha portat en aquesta línia de col.Jaboració, d'aliança objectiva entre forces polítiques rivals que cada any han de competir electoralment. La continuïtat dels resultats i el fet que els dos partits principals conservin la direcció d'institucions diferents continua mantenint la necessitat d'anar plegats en la realització del projecte.

Em sembla que això és el més original de l'aportació catalana des del punt de vista intern $i$ allò que, d'alguna manera, marca la politització dels nostres Jocs --tots els Jocs Olímpics n'estan des d'un punt de vista general- -, que és des del qual parlem. Així es produeix una situació en què la participacio no significa exclusió, però tampoc no significa ni debilitat d'execució ni unanimitat. I el procés és suficientment obert com per a poder ésser acceptat sense oposició per l'opinió pública del país.

Acabo de fer dues afirmacions: l'una és que aquest projecte de futur és un projecte necessàriament unitari, per bé que el seu desplegament en el temps coincideix amb competències electorals anuals de la política interior; l'altra és que ha estat el primer projecte, en cinquanta anys, que des de Barcelona ha estat rebut fora de Catalunya com un projecte comú. Tot i ésser un projecte de la ciutat de Barcelona, ni es deslligava, ni s'enfrontava amb Espanya, sinó que era un projecte impulsat i assumit també com un projecte espanyol, però que no amagava, sinó que posava en primer terme, que era un projecte de Barcelona, de la capital de Catalunya, i que, per tant, era un projecte catald.

Voldria afegir encara alguna cosa més en aquest sentit. No seria dolent que hom avancés encara un grau més en la politització del projecte, en aquest cas en l'àmbit internacional. Si com a projecte olímpic és un projecte internacional, si com a projecte de Barcelona és barceloní, català i espanyol, ¿no hauria d'ésser també un projecte de la Comunitat Europea?, ¿no hauria d'ésser un motiu perquè la Comunitat Europea aparegués amb una personalitat diferent dins dels Jocs Olímpics?, ¿no hauria d'ésser una oportunitat per a 
donar un petit pas simbòlic - la política consisteix també en símbols-i fer desfilar les delegacions europees darrera la bandera d'Europa? Ho desitjo, i crec que a Catalunya la iniciativa seria ben rebuda. Barcelona, com a ciutat dels Jocs, és la capital de Catalunya, una de les capitals d'Espanya i d'Europa; $i$ és amb aquest caràcter que forma part de la comunitat internacional. Per contra, hom pot argumentar que això seria polititzar els Jocs. No ho sé, en tot cas seria expressar millor la politització que nosaltres ja vivim dels Jocs i potser completaria el marc polític que fes possible que els Jocs de Barcelona, des de tots els punts de vista interns, fossin un èxit general. Expressaria millor la nostra complexitat i simplicitat, en afirmar-nos patriotes de Barcelona, de la nació catalana, d'Espanya i d'Europa. Potser sigui molta pàtria per tan poca gent, però potser val més tenir-ne un munt que tenir-ne només una i odiar totes les altres.

La descripció del marc polític té molts altres elements, però ara voldria incidir en algun altre, car em sembla que també són importants per a tot el procés. El primer consisteix en la coincidencia necessària de les administracions públiques en les actuacions que han de fer que els Jocs siguin possibles. El segon és l'existència d'un perill de desordre, com a consequìencia d'activitats terroristes. I, finalment, cal recordar l'existència dels riscos sempre presents de crisis internacionals que facin perillar la celebració dels Jocs. Tant des del punt de vista analític com des del punt de vista pràctic, no són negligibles, i hi faré una referència molt breu.

Vegem primer la participació d'administracions diferents en la creació de les infrastructures necessàries per als Jocs. A partir de les experiències viscudes en altres Estats federals o compostos, en especial des de Mont-real, la conclusió que n'han tret els organitzadors i els actors dels Jocs és que la col-laboració entre elles era indispensable. No només era bona en el procés de nominació, sinó en especial mentre es treballava per tal de portar-los a terme. És a dir, no ens podíem exposar a l'existència d'uns cartells que diguessin Mont-real i uns altres Mont-real-Canadà com a conseqüència d'enfontraments, sinó que tots havien de dir el mateix. Per tant, les diferents administracions actuants havien d'admetre una voluntat decisòria, la de la ciutat de Barcelona $i$, si escau, la del Comitè Olímpic.

L'organitzador dels Jocs havia de prendre les decisions, però aquestes havien d'intentar sumar i, en especial, fer rendibles les aportacions de tots. Des d'aquest punt de vista les dificultats han estat, són i seran - fins que s'acabin el Jocs - presents. Hom ha de pensar que en una ciutat on actuen quatre administracions, com a mínim, a més a més de les privades, existeix un rivell de complexitat notable per a adoptar decisions ràpides, eficaces i coherents. I, sobretot, si les actuacions cal fer-les en un timing prefixat, durant el qual la retirada o la ineficiencia d'una administració pot posar en perill el conjunt, 
malgrat que tots els altres actors hagin actuat amb correcció. Per si fos poc encara, el context temporal apareix marcat, com hem dit, per la celebració d'eleccions cada any. En conseqüència, el risc que en resulta no és insignificant.

Però fins avui el resultat és bo. L'actuació de les diverses administracions, considerada globalment, ha estat eftcaç $i$, malgrat les tensions politiques que puguin existir - $\mathrm{i}$ que han existit en alguns moments-, em sembla que l'acord sobre l'execució de les obres necessàries per a la celebració dels jocs Olímpics ha estat satisfactori. En un lloc actuen l'Administració de l'Estat Espanyol, la de la Generalitat de Catalunya, la de la Diputació provincial de Barcelona i la de la ciutat de Barcelona, i on a més actua amb puixança la iniciativa privada, la complexitat no ha afectat l'eficàcia, i crec que el resultat ha estat satisfactori, possiblement perquè s'ha generat una responsabilització molt intensa d'institucions i de partits. Tots ells han estat conscients que, per als ciutadans que representen, els Jocs eren importants i aquell que hagués volgut posar bastons a les rodes hauria estat castigat, car el projecte era acceptat, valorat i estimat per la immensa majoria de barcelonins, per la immensa majoria de catalans i per la immensa majoria d'espanyols. És probable que algú hagi pensat que si ell hagués volgut hauria pogut fer fracassar els Jocs, però també hauria d'haver pensat a continuació que aquell que els hagués fet fracassar hauria quedat possiblement esborrat de la vida pública, o com a mínim de les opcions amb aspiracions majoritàries.

En tot cas, l'actitud des de les institucions em sembla que ha estat de col-laboració oberta. Hom hi ha abocat esforços, diners i ajuts, de vegades fins i tot més enllà d'allí que seria esperable. Crec que l'execució tant de les obres públiques com del marc estructural sobre el qual estem edificant la Barcelona, i la Catalunya, de finals del segle xX, ofereix un balanç positiu, fins al punt que quan falten pocs mesos per a les eleccions municipals de la ciutat on se celebren els Jocs, la realització de les obres segueix el timing previst, no han sorgit dificultats suplementàries $i$, malgrat que la competència política principal és entre forces que dirigeixen institucions que han de col.taborar en la realizzació dels Jocs, no hi ha hagut situacions de bloqueig.

La segona qüestió és el terrorisme, possibilitat sempre present en qualsevol fet de gran ressò públic, més encara si s'ha de retransmetre a tot el món per televisió en directe. Les siruacions explosives de minories anorreades, amb impossibilitat de manifestació o de creació d'alternatives polítiques o estatals al món és força àmplia. El risc que qualsevol d'elles pugui esclatar en una ciutat olímpica, amb el plus d'impacte informatiu que, a més a més comporta, és un risc sempre present. És evident que hi ha riscs més liunyans i riscs més propers. Però també és evident que aquest no és un risc específic de Barcelona, sino dels Jocs com a tals. Fins ara aquesta quiestió s'ha dut amb 
flexibilitat i rigor, per tal d'evitar que la ciutat olímpica sigui objecte de la violència física o mental de forasters que vinguin a expressar llurs demandes en un aparador mundial.

La tercera quiestió és la possible repercussió de les tensions internacionals. Algunes es poden preveure, d'altres no. És evident que l'esfondrament del bloc soviètic i el canvi accelerat de l'URSS sense una perspectiva immediata. d'estabilització han provocat un capgirament del marc internacional. A partir de la II Guerra Mundial tots els Jocs Olimpics s'han celebrat dins d'una estructura mundial d'equilibri relatiu entre dues potències, basat en el terror, la negociació i el conflicte localitzat. A la guerra d'Iraq hem comprovat la inexistència d'un poder mundial capaç de controlar i d'orientar la solució d'un conflicte regional. Les circumstàncies han canviat, per a bé o per a mal, però serà la primera vegada que no existeixen dues potències que es temen $i$ que poden moure llurs peons diplomàtics o militars, tot mantenint un control sobre allò que s'esdevé a la major part del planeta. La situació és inèdita.

A la fi del segle XX cal articular un mecanisme que permeti un cert control preventiu i una certa capacitat resolutòria dels conflictes regionals. Que aquest mecanisme hagi d'ésser competència de les Nacions Unides és una cosa que no sé dir, però crec que és necessari i que seria convenient, perquè la pau i l'estabilitat en la lluita pel desenvolupament, per la llibertat dels pobles, per la dignitat humana de les persones és un valor internacional situat per sobre d'ideologies domèstiques o egoistes $i$, en tot cas, sembla que ho demanen les necessitats més primàries de subsistència de l'espècie humana, en una era històrica presidida per l'existència de l'arma nuclear.

He intentat d'oferir alguns trets relatius al marc polític, sempre mòbil i hipotètic, en què se situen els Jocs Olímpics de Barcelona, tant els més lligats a la ciutat com els més generals. Que hi incideixin poc o molt, caldrà veureho. Que els Jocs incideixin poc o molt en el marc polític nostre, en tot cas, seria desitjable en la mesura que un dels elements expressius dels Jocs és la voluntat de col.laboració entre tots els pobles i les persones de la Terra, per tal de conviure fraternalment $i$ de competir pacificament en condicions d'igualtat. 